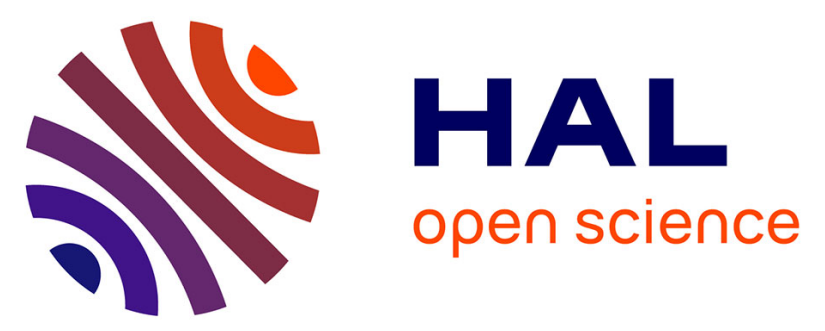

\title{
Educational inequalities in major depressive and generalized anxiety disorders: results from the French national SIP study
}

Marie Murcia, Jean-François Chastang, Isabelle Niedhammer

\section{- To cite this version:}

Marie Murcia, Jean-François Chastang, Isabelle Niedhammer. Educational inequalities in major depressive and generalized anxiety disorders: results from the French national SIP study. Social Psychiatry and Psychiatric Epidemiology, 2015, 50 (6), pp.919-928. 10.1007/s00127-015-1010-9 . hal01110460

\author{
HAL Id: hal-01110460 \\ https: / hal.sorbonne-universite.fr/hal-01110460
}

Submitted on 28 Jan 2015

HAL is a multi-disciplinary open access archive for the deposit and dissemination of scientific research documents, whether they are published or not. The documents may come from teaching and research institutions in France or abroad, or from public or private research centers.
L'archive ouverte pluridisciplinaire $\mathbf{H A L}$, est destinée au dépôt et à la diffusion de documents scientifiques de niveau recherche, publiés ou non, émanant des établissements d'enseignement et de recherche français ou étrangers, des laboratoires publics ou privés. 
Educational inequalities in major depressive and generalised anxiety disorders: results from the French national SIP study

Marie Murcia $^{1,2,3}$, Jean-François Chastang ${ }^{1,2}$, Isabelle Niedhammer ${ }^{1,2}$

${ }^{1}$ INSERM, UMR_S 1136, Pierre Louis Institute of Epidemiology and Public Health, Department of social epidemiology, F-75013, Paris, France

${ }^{2}$ Sorbonne Universités, UPMC Univ Paris 06, UMR_S 1136, Pierre Louis Institute of Epidemiology and Public Health, Department of social epidemiology, F-75013, Paris, France

${ }^{3}$ APST Centre, Blois, France

\section{Correspondence to:}

Dr. Isabelle Niedhammer

INSERM UMRS 1136 - IPLESP

Team 7 (ERES)

Faculté de Médecine Pierre et Marie Curie - pôle Saint-Antoine

27 rue de Chaligny

75012 Paris, France

E-mail: isabelle.niedhammer@inserm.fr

Word count of abstract: 247

Word count of text: 3339

Number of references: 33

Number of tables: 3

Number of figures: 2

\section{Conflict of interest statement}

On behalf of all authors, the corresponding author states that there is no conflict of interest. 


\section{ABSTRACT}

Objectives: Social inequalities in mental disorders have been reported; the lower the social position, the higher the prevalence of mental disorders. However, these inequalities have not always been observed and results may vary according to the indicator of social position, mental health outcome and population studied. The objective of this study was to examine the association between social position (educational level) and two mental disorders (Major Depressive -MDD- and General Anxiety Disorders -GAD-), measured using a structured diagnostic interview (MINI), and to evaluate the contribution of work status in the explanation of this association.

Methods: The study was based on a national representative sample of the French general population of 11777 people including 8072 workers. All analyses were done using weighted data. Bivariate Rao-Scott Chi-Square tests were conducted, and multivariate analysis was performed using weighted logistic regression analysis with adjustment for age.

Results: The prevalences of MDD/GAD and of less educated people were lower in the working population than in the non-working population. Educational inequalities were observed for MDD and GAD in the general population. Non-working status contributed to explain these inequalities by 23-28\% for MDD and by $23-37 \%$ for GAD when the less educated group was considered. Nonworking status was strongly associated with both disorders.

Conclusions: These results may improve our knowledge on educational inequalities in mental health and help to understand the discrepancies in the literature. Effort to preserve jobs and facilitate the return to employment may help to reduce social inequalities in mental health.

Key words: depression, anxiety, social position, educational level, social inequalities in mental health 


\section{Introduction}

Mental disorders affect more than a third of Europeans and one in four people in the world, and involved substantial consequences in terms of social and economic costs. Depressive and anxiety disorders are the most common mental disorders among the general population and represent a major public health concern $[1,2]$.

Social inequalities in health have been commonly observed in many countries; the lower the social position, the higher the prevalence of health problems. These inequalities have been underlined for various indicators of morbidity and mortality and various socioeconomic status (SES) indicators such as educational level, occupational group or income [3, 4].

Reviews of the literature suggest an association between SES and common mental disorders, especially depressive and anxiety disorders, among the general population; the lower the SES, the higher the prevalence of mental disorders [5-8]. This association was observed for one or more markers of SES, sometimes no clear trend was found, but no study showed a contrary trend according to the review by Fryers et al. [6]. Furthermore, a meta-analysis provides a summary OR of $1.81(p<0.001)$ for the association between low SES and depression [7]. However, not all studies retained in these reviews/meta-analysis used a structured diagnostic interview to measure mental health outcomes, but part of them used symptom scales/inventories.

If we focus on the literature using both diagnostic interview and education as SES marker among the general population, studies reported a significant association between low education and mood or depressive disorders [9-13], and some others did not [14, 15]. Similar conclusions may be drawn regarding anxiety disorders, although this outcome has been more rarely studied; studies observed educational inequalities in anxiety disorders [11-13], some others did not [9, 12], and one study reported an inverse association between education and anxiety, the prevalence of anxiety disorders increasing with higher levels of education [14].

Regarding the working population, the literature appears sparser, especially the studies using diagnostic interview. Some studies reported an association between low SES and mood or depressive and anxiety disorders [16, 17]. A study reported contrasting results depending on the SES marker used, the associations of mood and anxiety disorders being significant with income but not with education [18].

The disparities observed between the studies may be explained by various aspects: differences in the measure of mental health outcome, in the SES marker used, and in the population studied. Diagnostic interview has not been systematically used in the literature, making the comparison 
between studies difficult. In addition, anxiety disorders have been more seldom explored in the topic of social inequalities in mental disorders, the literature being more extensive regarding depressive disorders. The marker of SES may also be different according to the studies, as education, occupational group and income have been used. These markers may not be considered similar, and education may be considered as a more stable indicator, an earlier marker of social position that precedes other SES markers, leading to a clearer causality between SES and mental disorders, and may be available for all people even those who do not have an occupational title or income [19]. Finally, differences may be found between the studies because of differences in the population studied, especially regarding work status. Indeed, most previous studies on this topic were based on general population samples, and some studies were based on working population samples. In this study, we had the opportunity to compare the results on social inequalities in mental health for both depressive and anxiety disorders, and for the general, working and nonworking populations using the same survey data.

Our hypothesis was the following: social inequalities in mental health may be stronger among the general population than among the working population, and work status (non-working/working) may contribute to explain social inequalities in mental health in the general population. Consequently, our study may help to understand the discrepancies in the literature, further our knowledge on social inequalities in mental health and provide explanations on the mechanisms that may lead to these inequalities.

To bring new elements to the literature, the objective of this study was to explore the association between SES measured using educational level and both depressive and anxiety disorders measured using a structured diagnostic interview. An additional objective was to compare the results between the following populations: the working, non-working and general populations or in other words to evaluate the contribution of work status in the explanation of educational inequalities in depressive and anxiety disorders in the general population. To our knowledge, this type of analysis has never been done before.

\section{Materials and methods}

\section{Population}

The study was based on the data from the SIP (Santé et Itinéraire Professionnel) survey, conducted by the French Ministry of Labour (DARES), the French Ministry of Health (DRESS), the French Centre for Employment Studies (CEE) and the French National Institute for Statistics and Economic Studies (INSEE). The main objective of the survey was to improve the knowledge in the occupational determinants of health in the national French population [20]. The survey was based on a face-to-face questionnaire at respondent's home. The survey included a sample of the 
general population of 13648 participants (6195 men and 7453 women) aged 20-74 years in 2006 . The response rate was $76 \%$. For the purpose of this study, we restricted the sample to those aged less than 65, i.e. to those of working-age, leading to a sample of the general population of 11777 people (5346 men and 6431 women). Among this sample, there were 8072 workers (3916 men and 4156 women) and 3705 non-working people (1430 men and 2275 women). Previous studies by our team have already been published using these data [21-23]. The SIP survey was approved by the French ethics committees (CNIL and CNIS).

\section{Mental health outcomes}

Major Depressive Disorders (MDD) and General Anxiety Disorders (GAD) were measured using a structured diagnostic interview: the Mini International Neuropsychiatric Interview (MINI) [24]. It was based on the criteria and algorithms of the Diagnosis and Statistical Manual of Mental Disorders, 4th edition (DSM-IV).

\section{Social position}

Social position was measured by educational level using 4 groups: primary level, lower secondary level, higher secondary level and university.

\section{Covariates}

Age was studied in 4 groups: 20-29 years, 30-39 years, 40-49 years and 50-64 years.

\section{Statistical methods}

Weights were calculated using a calibration on margins (calibration variables were: age, gender, employment status, occupational groups, economic activities, urbanisation level and number of people in household) and inverse probability weighting to provide estimates representative of the population in 2006 [20]. All analyses were conducted using weighted data to control for a potential bias related to non-response and to provide representative results for the national population.

The associations between gender and MDD-GAD, age and educational level, between work status (non-working/working) and MDD-GAD, age and educational level, and between educational level and MDD-GAD were studied using Rao-Scott Chi-Square test. The associations between educational level and MDD-GAD were also explored using weighted logistic regression analysis with adjustment for age, MDD and GAD being the dependent variables. All analyses were carried out for the three populations: the working population, the non-working population and the general population.

A comparison between two models was performed among the general population: model 1 including age and educational level as independent variables and MDD/GAD as dependent 
variable, and an extended model including work status as an additional independent variable. The contribution of work status to the explanation of educational inequalities in MDD/GAD was estimated by the change in the OR associated with the lowest educational level after inclusion of work status in the model, i.e. explained fraction calculated by the formula:

$\left(\mathrm{OR}_{\text {model } 1}-\mathrm{OR}_{\text {extended model }}\right) /\left(\mathrm{OR}_{\text {model } 1}-1\right) \times 100$

Positive \% values indicate reductions in the OR. This explained fraction has commonly been used in the literature to evaluate the contribution of a factor or a set of factors in the explanation of social inequalities in health outcomes [25-27]. As the data were weighted, the Jackknife method was used as a resampling technique to obtain $95 \% \mathrm{Cl}$ for the explained fractions [28].

All analyses were carried out separately for men and women using STATA and SAS softwares.

\section{Results}

The description of the three populations, the working, non-working and general populations, are presented in Table 1. For all three populations, MDD and GAD were significantly more prevalent among women than among men, a result that was expected. The prevalence of both disorders was higher for the non-working population than for the working population $(p<0.001)$. A high comorbidity was observed between MDD and GAD, 38\% of men and women having a MDD had also a diagnostic of GAD and $42 \%$ of men and women having a GAD had also a diagnostic of MDD among the working population. These figures were respectively $46 \%$ and $58 \%$ among the non-working population and $42 \%$ and $49 \%$ among the general population. The age distribution was significantly different between the working and non-working populations, the non-working population being more likely to be both younger and older $(p<0.001)$. Significant differences in the distribution of educational level between genders were observed for both populations; women were more likely to be more educated than men, as expected. The distribution of educational level was different between the working and non-working populations, the working population being more educated $(p<0.001)$.

Table 2 showed that the prevalence of MDD increased with decreasing educational level among men in the general population only. The prevalence of MDD increased with decreasing educational level among women for the three populations. Educational level displayed a non-linear association with GAD among men in the working population. The prevalence of GAD increased with decreasing educational level among women in the non-working and general population. The prevalence of both disorders was higher for the general population and still more for the nonworking population than for the working population for all educational levels, particularly for the less educated (Figures 1-2). 
The associations between educational level and MDD/GAD with adjustment for age are presented in Table 3. The risk of MDD increased with low educational level among men for the general population only. The risk of MDD increased with low educational level among women for the three populations. Education was associated with GAD among men in the working population, but the association was not linear. The risk of GAD increased with the lowest educational level among men and women in the general population. The inclusion of work status as an additional independent variable in the extended models led to reduce the OR associated with the lowest educational level substantially: the OR of MDD associated with the lowest educational level was reduced by $28 \%$ for men and $23 \%$ for women, and the OR of GAD by $23 \%$ for men and $37 \%$ for women. These contributions (explained fractions) were all significant. In addition, non-working status was associated with both disorders among both genders.

\section{Discussion}

\section{Main results}

The prevalences of MDD/GAD and of less educated people were lower in the working population than in the non-working population. Educational differences in MDD and GAD were observed, the lower the educational level, the higher the prevalence of MDD and GAD for both genders among the general population. These educational inequalities were strongly reduced after taking work status into account. Thus, educational inequalities in mental disorders were more marked in the general population than in the working population, and this may be explained by the non-working population that contributed to increase educational inequalities in mental disorders in the general population.

\section{Comparison with literature}

The working population was found to have a lower prevalence of mental disorders than the nonworking population confirming previous results reporting a protective role of employment status in the prevalence of mental disorders [9, 10]. Furthermore, our study showed a higher prevalence of mental disorders for women than for men, in agreement with the literature $[7,8,10,16]$.

Studies exploring social inequalities in mental disorders using diagnostic interview and educational level as a marker of SES have been rare among the general population, and even more seldom among the working population. Furthermore, to our knowledge, no previous study compared social inequalities in mental disorders between the working and general populations, and evaluated the contribution of work status in the explanation of these inequalities. The comparison with the literature is thus limited to the studies that explored these inequalities either among the general population, or among the working population. 
The literature review by Fryers et al. [5] suggest that the prevalence of common mental disorders is more likely to increase with decreasing SES than the reverse among the general population. Our results are in line with this conclusion for both MDD and GAD. Indeed, the ORs of MDD associated with the lowest level of education were 2.32 (95\% Cl: 1.43-3.77) for men and 2.05 (95\% Cl: 1.542.72) for women, results that are consistent with the summary OR of 1.81 (95\% Cl: 1.57-2.10) reported in the meta-analysis by Lorant et al. [7], that included all studies exploring the association between low educational level and depression, measured using either diagnostic interview or symptom scales/inventories. Our results are in line with studies reporting a significant association between low education and mood or depressive disorders measured using diagnostic interview among the general population [9-13]. The lowest educational level was associated with GAD among the general population in our study. Some rare previous studies exploring the association between education and anxiety disorders measured using diagnostic interview reported either a significant association [11-13] or a non-significant association [9, 12].

Regarding the working population, the number of studies examining the association between SES and mental disorders using diagnostic interview is even lower. A significant association between education and MDD was observed in our study among women only. Two previous studies reported an association between low SES and mood or depressive and anxiety disorders [16, 17]. A study reported contrasting results depending on the SES marker used, the associations of mood and anxiety disorders being significant with income but not with education [18].

Our study may be the first one to explore educational inequalities in depressive and anxiety disorders measured using a diagnostic interview among both the working population and the general population. In agreement with the review by Lorant et al. [7], the interpretation of the association between education and these two disorders among the general population is likely to be the following: the lower the educational level, the higher the prevalence of these disorders. Our study adds to the literature in showing that educational inequalities in depressive and anxiety disorders are likely to be more marked among the general population than among the working population and more pronounced for depressive disorders than for anxiety disorders. Our study also underlines that work status may contribute substantially to explain educational inequalities in both disorders in the general population.

The differences in the associations between educational level and MDD/GAD between the working and general populations and the contribution of work status in the explanation of educational inequalities in these disorders may be explained by different potential explanations:

(1) The distribution of educational level was different between the working and non-working populations. Indeed, the working population was more likely to be more educated, something that 
may reduce the spectrum of educational level distribution and consequently the magnitude of educational inequalities in mental disorders among the working population. In other words, the less educated people are more likely to be non-workers. This result is in agreement with European statistics (Source: Eurostat) showing that the employment rate increased from $52.1 \%$ to $83.4 \%$ and the unemployment rate decreased from $17.9 \%$ to $5.9 \%$ with increasing educational level across the EU-28 in 2013.

(2) A healthy worker effect may contribute to the differences in social inequalities in mental health between the working and general populations. Indeed, the association between low education and the two disorders might be underestimated among the working population if low educated people suffering from these disorders were more likely to leave their job.

(3) Employment may be beneficial for health, particularly for depression and general mental health as underlined by a recent review by van der Noordt et al. [29]. These authors state that among the positive health effects of employment, there may be: 'structure of the day, financial security, opportunities to increase skills, interaction with others, meaningful life goals, and purpose and providing a sense of personal achievement'.

(4) Unemployment, as other types of divestment passages, may have consequences on mental health, as underlined by the review by Ezzi et al. [30]. More recently, Berkman [31] in her commentary of the study by Riumallo-Herl et al. [32] summarized 'the three kinds of loss that may accompany the loss of a job and may be central to affecting health and well-being: (i) financial loss with social protection as a potential buffer; (ii) loss of identity and meaning with loss of such a major role; and (iii) loss of social interaction and engagement with a community of workers'.

These explanations may explain why educational inequalities in mental disorders may be more marked in the general population than in the working population, and why non-working status may contribute to explain these inequalities in the general population.

\section{Strengths and limitations of the study}

The strengths of the study may be highlighted. The response rate was $76 \%$ and may be considered satisfactory. The SIP survey was based on a national sample of the French population, and as weighted data were used in our study, we were able to control for a potential non-response bias and provide representative results that may be extrapolated to the French population. The sample size was large and allowed to study men and women separately as recommended previously [33]. Another major strength of the study was the use of a structured diagnostic interview for both depressive and anxiety disorders. Diagnostic interviews have seldom been used among the general population and even more seldom among the working population in the topic of social inequalities in mental disorders. Muntaner et al. underlined the need of diagnostic interviews in this topic [8]. In addition, our study explored anxiety disorders, understudied in the topic of social inequalities in mental disorders in comparison with depressive disorders. Social position was 
measured using educational level, that may be considered as an early marker of SES that may reduce the risk of inverse causality and is available for all people even those who do not work [19]. Other strengths were the comparison of the results on educational inequalities in mental disorders between different populations (general, working and non-working) and the evaluation of the contribution of work status in the explanation of these inequalities, that has never been done before. Finally, sophisticated statistical methods were used including weighted statistical analyses and the Jackknife method to provide confidence intervals for the contribution of work status in the explanation of educational inequalities in mental disorders.

A limitation of this study may be related to the cross-sectional study design. However, as educational level was used as a SES marker, the direction of the association is more likely to be from education to mental disorders than the reverse. A high comorbidity was observed between the two disorders and the separate analysis of depressive and anxiety disorders without comorbid cases may be difficult due to a lack of statistical power. Despite this comorbidity, differences in the results were observed for depressive and anxiety disorders.

\section{Conclusion}

This study brings new elements on educational inequalities in depressive and anxiety disorders among both the working and general populations. The associations between educational level and the two disorders were stronger among the general population than among the working population and for depressive disorders more than for anxiety disorders. We clearly demonstrated that nonworking status may contribute to explain educational inequalities in mental disorders in the general population. More research may be needed to better understand these inequalities and to confirm the differences between the working and general populations and between the two disorders. Furthermore, as non-working status may play a substantial role in explaining social inequalities in mental health, effort towards preserving jobs and facilitating the return to employment may help to reduce these inequalities.

\section{Acknowledgements}

The authors thank the members of the DARES, DREES, CEE and INSEE, and all the people who participated to the SIP survey and made this study possible. This study was founded by the French ministry of labour (DARES, grant no 2200727156). 


\section{References}

1. Hoffman DL, Dukes EM, Wittchen HU. Human and economic burden of generalized anxiety disorder. Depress Anxiety 2008; 25(1):72-90.

2. Ustun TB, Ayuso-Mateos JL, Chatterji S, Mathers C, Murray CJ. Global burden of depressive disorders in the year 2000. Br J Psychiatry 2004; 184:386-392.

3. Dalstra JA, Kunst AE, Borrell C, Breeze E, Cambois E, Costa G, et al. Socioeconomic differences in the prevalence of common chronic diseases: an overview of eight European countries. Int J Epidemiol 2005; 34(2):316-326.

4. Huisman M, Kunst AE, Bopp M, Borgan JK, Borrell C, Costa G, et al. Educational inequalities in cause-specific mortality in middle-aged and older men and women in eight western European populations. Lancet 2005; 365(9458):493-500.

5. Fryers T, Melzer D, Jenkins R. Social inequalities and the common mental disorders: a systematic review of the evidence. Soc Psychiatry Psychiatr Epidemiol 2003; 38(5):229-237.

6. Fryers T, Melzer D, Jenkins R, Brugha T. The distribution of the common mental disorders: social inequalities in Europe. Clin Pract Epidemol Ment Health 2005; 1:14.

7. Lorant V, Deliege D, Eaton W, Robert A, Philippot P, Ansseau M. Socioeconomic inequalities in depression: a meta-analysis. Am J Epidemiol 2003; 157(2):98-112.

8. Muntaner C, Eaton WW, Miech R, O'Campo P. Socioeconomic position and major mental disorders. Epidemiol Rev 2004; 26:53-62.

9. Alonso J, Angermeyer MC, Bernert S, Bruffaerts R, Brugha TS, Bryson H, et al. Prevalence of mental disorders in Europe: results from the European Study of the Epidemiology of Mental Disorders (ESEMeD) project. Acta Psychiatr Scand Suppl 2004(420):2127.

10. Andersen I, Thielen K, Nygaard E, Diderichsen F. Social inequality in the prevalence of depressive disorders. J Epidemiol Community Health 2009; 63(7):575-581.

11. Chazelle E, Lemogne C, Morgan K, Kelleher CC, Chastang JF, Niedhammer I. Explanations of educational differences in major depression and generalised anxiety disorder in the Irish population. J Affect Disord 2011; 134(1-3):304-314.

12. Muntaner C, Eaton WW, Diala C, Kessler RC, Sorlie PD. Social class, assets, organizational control and the prevalence of common groups of psychiatric disorders. Soc Sci Med 1998; 47(12):2043-2053.

13. Bijl RV, Ravelli A, van ZG. Prevalence of psychiatric disorder in the general population: results of The Netherlands Mental Health Survey and Incidence Study (NEMESIS). Soc Psychiatry Psychiatr Epidemiol 1998; 33(12):587-595.

14. Pinto-Meza A, Moneta MV, Alonso J, Angermeyer MC, Bruffaerts R, Caldas de Almeida $\mathrm{JM}$, et al. Social inequalities in mental health: results from the EU contribution to the World Mental Health Surveys Initiative. Soc Psychiatry Psychiatr Epidemiol 2013; 48(2):173-181. 
15. Skapinakis P, Weich S, Lewis G, Singleton N, Araya R. Socio-economic position and common mental disorders. Longitudinal study in the general population in the UK. Br J Psychiatry 2006; 189:109-117.

16. Cohidon C, Imbernon E, Gorldberg M. Prevalence of common mental disorders and their work consequences in France, according to occupational category. Am J Ind Med 2009; 52(2):141-152.

17. Virtanen M, Koskinen S, Kivimaki M, Honkonen T, Vahtera J, Ahola K, et al. Contribution of non-work and work-related risk factors to the association between income and mental disorders in a working population: the Health 2000 Study. Occup Environ Med 2008; 65(3):171-178.

18. Pulkki-Raback L, Ahola K, Elovainio M, Kivimaki M, Hintsanen M, Isometsa E, et al. Socioeconomic position and mental disorders in a working-age Finnish population: the health 2000 study. Eur J Public Health 2012; 22(3):327-332.

19. Galobardes B, Shaw M, Lawlor DA, Lynch JW, Davey SG. Indicators of socioeconomic position (part 1). J Epidemiol Community Health 2006; 60(1):7-12.

20. Coutrot T, Rouxel C, Bahu M, Herbet JB, Mermilliod C. Parcours professionnel et état de santé. Premières Informations et Premières Synthèses 2010; 1.

21. Murcia M, Chastang JF, Niedhammer I. Psychosocial work factors, major depressive and generalised anxiety disorders: Results from the French national SIP study. J Affect Disord 2013; 146(3):319-327.

22. Malard L, Chastang J-F, Niedhammer I. Changes in psychosocial work factors in the French working population between 2006 and 2010. Int Arch Occup Environ Health 2014; (in press).

23. Niedhammer I, Chastang J-F. Psychosocial work factors and first depressive episode: retrospective results from the French national SIP survey. Int Arch Occup Environ Health 2014; (in press).

24. Sheehan DV, Lecrubier $\mathrm{Y}$, Sheehan $\mathrm{KH}$, Amorim $\mathrm{P}$, Janavs J, Weiller $\mathrm{E}$, et al. The MiniInternational Neuropsychiatric Interview (M.I.N.I.): the development and validation of a structured diagnostic psychiatric interview for DSM-IV and ICD-10. J Clin Psychiatry 1998; 59 Suppl 20:22-33.

25. Schrijvers CT, van de Mheen HD, Stronks K, Mackenbach JP. Socioeconomic inequalities in health in the working population: the contribution of working conditions. Int $\mathrm{J}$ Epidemiol 1998; 27(6):1011-1018.

26. Niedhammer I, Chastang JF, David S, Kelleher C. The contribution of occupational factors to social inequalities in health: findings from the national French SUMER survey. Soc Sci Med 2008; 67(11):1870-1881.

27. Niedhammer I, Bourgkard E, Chau N. Occupational and behavioural factors in the explanation of social inequalities in premature and total mortality: a 12.5-year followup in the Lorhandicap study. Eur J Epidemiol 2011; 26(1):1-12.

28. Lohr SL. Sampling: Design and Analysis, Second Edition: Pacific Grove, CA: Duxbury Press; 2009. 
29. van der Noordt M, IJzelenberg H, Droomers M, Proper KI. Health effects of employment: a systematic review of prospective studies. Occup Environ Med 2014; 71(10):730736.

30. Ezzi D. Unemployment and mental health: a critical review. Soc Sci Med 1993; 37(1):41-52.

31. Berkman LF. Commentary: The hidden and not so hidden benefits of work: identity, income and interaction. Int J Epidemiol 2014.

32. Riumallo-Herl C, Basu S, Stuckler D, Courtin E, Avendano M. Job loss, wealth and depression during the Great Recession in the USA and Europe. Int J Epidemiol 2014.

33. Niedhammer I, Saurel-Cubizolles MJ, Piciotti M, Bonenfant S. How is sex considered in recent epidemiological publications on occupational risks? Occup Environ Med 2000; 57(8):521-527. 
Table 1 Description of the study sample according to mental disorders, age and educational level for the working, non-working and general population

\begin{tabular}{|c|c|c|c|c|c|}
\hline \multirow[t]{2}{*}{ Working population } & \multicolumn{2}{|c|}{ MEN ( $N=3916)$} & \multicolumn{2}{|c|}{ WOMEN (N=4156) } & \multirow[t]{2}{*}{$p^{c}$} \\
\hline & $\mathrm{n}^{\mathrm{a}}$ & $\%^{b}$ & $\mathrm{n}^{\mathrm{a}}$ & $\%^{\mathrm{b}}$ & \\
\hline Major depressive disorder (MDD) & 149 & 3.43 & 327 & 7.46 & 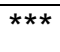 \\
\hline $\begin{array}{l}\text { Generalized anxiety disorder (GAD) } \\
\text { Age (v) }\end{array}$ & 130 & 3.42 & 282 & 6.31 & 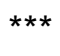 \\
\hline Age $(y)$ & & & & & ns \\
\hline $20-29$ & 550 & 19.02 & 541 & 18.39 & \\
\hline $30-39$ & 1013 & 27.87 & 1077 & 26.68 & \\
\hline $40-49$ & 1166 & 28.52 & 1341 & 29.64 & \\
\hline $50-64$ & 1187 & 24.60 & 1197 & 25.29 & \\
\hline Educational level & & & & & *** \\
\hline University & 1076 & 30.63 & 1490 & 36.56 & \\
\hline Higher secondary & 640 & 17.76 & 778 & 19.40 & \\
\hline Lower secondary & 1728 & 40.79 & 1440 & 34.00 & \\
\hline Primary & 463 & 10.83 & 431 & 10.04 & \\
\hline \multirow[t]{2}{*}{ Non-working population } & \multicolumn{2}{|c|}{ MEN (N=1430) } & \multicolumn{2}{|c|}{ WOMEN ( $\mathrm{N}=2275)$} & $p^{c}$ \\
\hline & $\mathrm{n}^{\mathrm{a}}$ & $\%^{b}$ & $\mathrm{n}^{\mathrm{a}}$ & $\%^{\mathrm{b}}$ & \\
\hline Major depressive disorder (MDD) & 111 & 7.56 & 315 & 12.61 & 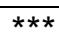 \\
\hline Generalized anxiety disorder (GAD) & 87 & 5.72 & 244 & 10.27 & *** \\
\hline Age $(y)$ & & & & & *** \\
\hline $20-29$ & 259 & 28.58 & 438 & 25.06 & \\
\hline $30-39$ & 116 & 10.09 & 326 & 16.59 & \\
\hline $40-49$ & 129 & 9.20 & 340 & 14.72 & \\
\hline $50-64$ & 926 & 52.14 & 1171 & 43.63 & \\
\hline Educational level & & & & & ** \\
\hline University & 234 & 21.19 & 485 & 25.87 & \\
\hline Higher secondary & 169 & 14.29 & 343 & 16.70 & \\
\hline Lower secondary & 525 & 37.69 & 754 & 32.98 & \\
\hline Primary & 423 & 26.83 & 587 & 24.45 & \\
\hline \multirow[t]{2}{*}{ General population } & \multicolumn{2}{|c|}{ MEN (N=5346) } & \multicolumn{2}{|c|}{ WOMEN (N=6431) } & \\
\hline & $\mathrm{n}^{\mathrm{a}}$ & $\%^{b}$ & $\mathrm{n}^{\mathrm{a}}$ & $\%^{\mathrm{b}}$ & $p^{2}$ \\
\hline Major depressive disorder (MDD) & 260 & 4.47 & 642 & 9.31 & 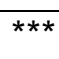 \\
\hline Generalized anxiety disorder (GAD) & 217 & 4.00 & 526 & 7.73 & *** \\
\hline Age $(y)$ & & & & & ns \\
\hline $20-29$ & 809 & 21.43 & 979 & 20.79 & \\
\hline $30-39$ & 1129 & 23.39 & 1403 & 23.05 & \\
\hline $40-49$ & 1295 & 23.64 & 1681 & 24.27 & \\
\hline $50-64$ & 2113 & 31.54 & 2368 & 31.89 & \\
\hline \multirow[t]{5}{*}{ Educational level } & & & & & *** \\
\hline & 1310 & 28.39 & 1975 & 32.86 & \\
\hline & 809 & 16.94 & 1121 & 18.47 & \\
\hline & 2253 & 40.05 & 2194 & 33.64 & \\
\hline & 886 & 14.62 & 1018 & 15.03 & \\
\hline
\end{tabular}

a Non-weighted number of individuals

${ }^{\mathrm{b}}$ Weighted frequency

${ }^{c}$ Rao-Scott Chi-Square test, ***: $p<0.001,{ }^{\star *}: p<0.01,{ }^{*}: p<0.05$, ns: non-significant 
Table 2 Association between educational level and MDD/GAD among the working, non-working and general population

\begin{tabular}{|c|c|c|c|c|c|c|c|c|}
\hline \multirow{3}{*}{ Working population } & \multicolumn{4}{|c|}{ MDD } & \multicolumn{4}{|c|}{ GAD } \\
\hline & \multicolumn{2}{|c|}{$\begin{array}{c}\text { Men } \\
(\mathrm{N}=3907)\end{array}$} & \multicolumn{2}{|c|}{$\begin{array}{c}\text { Women } \\
(\mathrm{N}=4139)\end{array}$} & \multicolumn{2}{|c|}{$\begin{array}{c}\text { Men } \\
(\mathrm{N}=3907)\end{array}$} & \multicolumn{2}{|c|}{$\begin{array}{c}\text { Women } \\
(\mathrm{N}=4139)\end{array}$} \\
\hline & $\mathrm{n}^{\mathrm{a}}$ & $\%^{\mathrm{b}}$ & $\mathrm{n}^{\mathrm{a}}$ & $\%^{\mathrm{b}}$ & $\mathrm{n}^{\mathrm{a}}$ & $\%^{\mathrm{b}}$ & $n^{a}$ & $\%^{\mathrm{b}}$ \\
\hline Educational level & \multicolumn{3}{|c|}{ ns } & ** & \multicolumn{3}{|c|}{ * } & ns \\
\hline University & 27 & 2.32 & 90 & 5.29 & 30 & 2.43 & 97 & 5.92 \\
\hline Higher secondary & 23 & 3.26 & 60 & 7.40 & 16 & 3.07 & 50 & 6.15 \\
\hline Lower secondary & 80 & 4.34 & 132 & 9.19 & 71 & 4.54 & 98 & 6.54 \\
\hline Primary & 19 & 3.46 & 44 & 9.57 & 13 & 2.59 & 36 & 7.36 \\
\hline \multirow[t]{2}{*}{ Non-working population } & \multicolumn{2}{|c|}{$\begin{array}{c}\text { Men } \\
(\mathrm{N}=1351)\end{array}$} & \multicolumn{2}{|c|}{$\begin{array}{c}\text { Women } \\
(\mathrm{N}=2169)\end{array}$} & \multicolumn{2}{|c|}{$\begin{array}{c}\text { Men } \\
(\mathrm{N}=1351)\end{array}$} & \multicolumn{2}{|c|}{$\begin{array}{c}\text { Women } \\
(\mathrm{N}=2169)\end{array}$} \\
\hline & $\mathrm{n}^{\mathrm{a}}$ & $\%^{\mathrm{b}}$ & $\mathrm{n}^{\mathrm{a}}$ & $\%^{\mathrm{b}}$ & $\mathrm{n}^{\mathrm{a}}$ & $\%^{\mathrm{b}}$ & $\mathrm{n}^{\mathrm{a}}$ & $\%^{\mathrm{b}}$ \\
\hline Educational level & \multicolumn{3}{|c|}{ ns } & $\star \star \star *$ & \multicolumn{3}{|c|}{ ns } & * \\
\hline University & 12 & 6.16 & 40 & 8.73 & 15 & 5.67 & 39 & 8.52 \\
\hline Higher secondary & 10 & 5.85 & 39 & 9.86 & 8 & 4.53 & 30 & 7.29 \\
\hline Lower secondary & 45 & 8.58 & 122 & 14.43 & 28 & 4.85 & 86 & 11.01 \\
\hline Primary & 42 & 9.84 & 104 & 17.02 & 34 & 8.34 & 79 & 13.40 \\
\hline \multirow[t]{2}{*}{ General population } & \multicolumn{2}{|c|}{$\begin{array}{c}\text { Men } \\
(N=5258)\end{array}$} & \multicolumn{2}{|c|}{$\begin{array}{c}\text { Women } \\
(\mathrm{N}=6308)\end{array}$} & \multicolumn{2}{|c|}{$\begin{array}{c}\text { Men } \\
(N=5258)\end{array}$} & \multicolumn{2}{|c|}{$\begin{array}{c}\text { Women } \\
(\mathrm{N}=6308)\end{array}$} \\
\hline & $\mathrm{n}^{\mathrm{a}}$ & $\%^{\mathrm{b}}$ & $\mathrm{n}^{\mathrm{a}}$ & $\%^{\mathrm{b}}$ & $\mathrm{n}^{\mathrm{a}}$ & $\%^{\mathrm{b}}$ & $\mathrm{n}^{\mathrm{a}}$ & $\%^{\mathrm{b}}$ \\
\hline \multirow[t]{4}{*}{ Educational level } & \multicolumn{3}{|c|}{$\star \star$} & 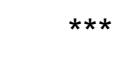 & \multicolumn{3}{|c|}{ ns } & ** \\
\hline & 39 & 3.00 & 130 & 6.23 & 45 & 3.01 & 136 & 6.63 \\
\hline & 33 & 3.78 & 99 & 8.17 & 24 & 3.36 & 80 & 6.51 \\
\hline & 125 & 5.29 & 254 & 10.97 & 99 & 4.61 & 184 & 8.06 \\
\hline Primary & 61 & 6.23 & 148 & 13.77 & 47 & 5.09 & 115 & 10.76 \\
\hline
\end{tabular}


Table 3 Association between education level and MDD/GAD in the working, non-working and general population, with adjustment for age and contribution of work status in the explanation of educational inequalities in MDD/GAD

\begin{tabular}{|c|c|c|c|c|c|c|c|c|c|c|c|c|c|}
\hline & & \multicolumn{5}{|c|}{ MDD } & \multicolumn{7}{|c|}{ GAD } \\
\hline & & \multicolumn{2}{|r|}{ MEN } & \multicolumn{3}{|r|}{ WOMEN } & \multicolumn{3}{|r|}{ MEN } & \multicolumn{4}{|c|}{ WOMEN } \\
\hline & & OR & $95 \% \mathrm{Cl}$ & $\mathbf{p}$ & OR & $95 \% \mathrm{Cl}$ & $\mathbf{p}$ & OR & $95 \% \mathrm{Cl}$ & $\mathbf{p}$ & OR & $95 \% \mathrm{Cl}$ & p \\
\hline \multirow[t]{5}{*}{ Working population } & Educational level & & $N=3907$ & ns & & $\mathrm{N}=4139$ & * & & $\mathrm{N}=3907$ & * & & $\mathrm{N}=4139$ & ns \\
\hline & University & 1 & & & 1 & & & 1 & & & 1 & & \\
\hline & Higher secondary & 1.36 & {$[0.73-2.56]$} & & 1.39 & {$[0.95-2.01]$} & & 1.29 & [0.63 - 2.64] & & 1.01 & {$[0.67-1.51]$} & \\
\hline & Lower secondary & 1.90 & {$[1.12-3.21]$} & & 1.62 & {$[1.18$ - 2.23] } & & 1.97 & {$[1.19-3.28]$} & & 0.98 & {$[0.71-1.37]$} & \\
\hline & Primary & 1.61 & {$[0.81-3.21]$} & & 1.57 & [1.03 - 2.39] & & 1.07 & {$[0.52-2.20]$} & & 1.02 & {$[0.67-1.57]$} & \\
\hline \multirow{5}{*}{$\begin{array}{l}\text { Non-working } \\
\text { population }\end{array}$} & Educational level & & $\mathrm{N}=1351$ & ns & & $N=2169$ & ** & & $N=1351$ & ns & & $N=2169$ & ns \\
\hline & University & 1 & & & 1 & & & 1 & & & 1 & & \\
\hline & Higher secondary & 0.90 & {$[0.33 ; 2.46]$} & & 1.08 & {$[0.64 ; 1.83]$} & & 0.84 & {$[0.29 ; 2.41]$} & & 0.81 & {$[0.48 ; 1.38]$} & \\
\hline & Lower secondary & 1.24 & {$[0.61 ; 2.54]$} & & 1.60 & {$[1.04 ; 2.45]$} & & 0.84 & {$[0.40 ; 1.77]$} & & 1.22 & {$[0.79 ; 1.88]$} & \\
\hline & Primary & 1.80 & {$[0.84 ; 3.85]$} & & 1.92 & {$[1.23 ; 2.99]$} & & 1.80 & {$[0.84 ; 3.90]$} & & 1.54 & {$[0.99 ; 2.38]$} & \\
\hline \multirow{5}{*}{$\begin{array}{l}\text { General population } \\
\text { (model 1) }\end{array}$} & Educational level & & $N=5258$ & $* \star$ & & $N=6308$ & 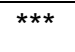 & & $N=5258$ & ns & & $\mathrm{N}=6308$ & ns \\
\hline & University & 1 & & & 1 & & & 1 & & & 1 & & \\
\hline & Higher secondary & 1.27 & {$[0.74 ; 2.17]$} & & 1.29 & {$[0.96 ; 1.75]$} & & 1.13 & {$[0.62 ; 2.05]$} & & 0.95 & {$[0.69 ; 1.30]$} & \\
\hline & Lower secondary & 1.82 & {$[1.19 ; 2.77]$} & & 1.69 & {$[1.31 ; 2.18]$} & & 1.60 & {$[1.05 ; 2.43]$} & & 1.12 & {$[0.87 ; 1.45]$} & \\
\hline & Primary & 2.32 & {$[1.43 ; 3.77]$} & & 2.05 & {$[1.54 ; 2.72]$} & & 1.81 & {$[1.11 ; 2.96]$} & & 1.46 & {$[1.08 ; 1.95]$} & \\
\hline \multirow{6}{*}{$\begin{array}{l}\text { General population } \\
\text { + work status } \\
\text { (extended model) }\end{array}$} & Educational level & & $N=5258$ & * & & $N=6308$ & 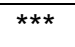 & & $N=5258$ & ns & & $\mathrm{N}=6308$ & ns \\
\hline & University & 1 & & & 1 & & & 1 & & & 1 & & \\
\hline & Higher secondary & 1.26 & {$[0.74 ; 2.17]$} & & 1.26 & {$[0.93 ; 1.71]$} & & 1.12 & {$[0.62 ; 2.04]$} & & 0.92 & {$[0.67 ; 1.27]$} & \\
\hline & Lower secondary & 1.76 & {$[1.14 ; 2.70]$} & & 1.63 & {$[1.26 ; 2.10]$} & & 1.55 & {$[1.01 ; 2.39]$} & & 1.08 & {$[0.83 ; 1.40]$} & \\
\hline & Primary & 1.95 & {$[1.19 ; 3.21]$} & & 1.80 & {$[1.35 ; 2.41]$} & & 1.63 & {$[0.99 ; 2.67]$} & & 1.29 & {$[0.96 ; 1.73]$} & \\
\hline & Non-working vs working & 2.76 & {$[1.92 ; 3.95]$} & 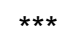 & 1.68 & {$[1.37 ; 2.07]$} & 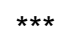 & 1.83 & {$[1.25 ; 2.66]$} & $\star \star$ & 1.63 & {$[1.31 ; 2.04]$} & 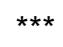 \\
\hline \multirow{2}{*}{$\begin{array}{l}\text { Explained fraction (EF) } \\
(\%)^{a}\end{array}$} & & $\mathrm{EF}$ & $95 \% \mathrm{Cl}$ & & $\mathrm{EF}$ & $95 \% \mathrm{Cl}$ & & $\mathrm{EF}$ & $95 \% \mathrm{Cl}$ & & $\mathrm{EF}$ & $95 \% \mathrm{Cl}$ & \\
\hline & Primary versus university & 27.98 & {$[11.05 ; 44.90]$} & & 23.38 & {$[11.94 ; 34.83]$} & & 22.88 & {$[2.07 ; 43.68]$} & & 36.78 & {$[8.66 ; 64.90]$} & \\
\hline
\end{tabular}

Weighted logistic regression analysis OR: Odds-ratio adjusted for age

In bold: OR or explained fraction (EF) significant at 5\%

$\star * *: p<0.001, * *: p<0.01, *: p<0.05$, ns: non-significant

${ }^{a}\left(\mathrm{OR}_{\text {model } 1}-\mathrm{OR}_{\text {extended model }}\right) /\left(\mathrm{OR}_{\text {model } 1}-1\right) \times 100$ 